or parts brought under the influence of either the negative or positive pole alone as desired. Static electricity (positive) is also sometimes useful in chorea in calming nervous excitement and as an aid to nutrition.

But the two methods that I have found, on the whole, to be the most effective in the treatment of chorea are central galvanization and general faradi. zation. These two methods properly differentiated and used either alone or in alternation, according to the indications in each individual case, are capable of doing much, not only in alleviating the violence of the choreic movements, but in shortening the duration of the disease.

A somewhat useful point in the way of differential indication for the use of the two currents and the two methods of application, which has been forced upon me by repeated observation, is the following: For children of full habits and in that excellent condition of general health which we not infrequently see among the victims of chorea, the galvanic current is to be preferred. For those, on the contrary, who are weak and anemic, with impaired nutrition, the faradic current is far more grateful, and is followed by better results, both immediate and permanent.

\section{EPILEPSY CURED BY TENOTOMY OF THE OCULAR MUSCLES.}

Read in the Section on Neurology and Medical Jurisprudence at the Forty-sixth Anumal Meeting of the American Medical Ascociation, at Baltimore, MId, May 7-10, 1895.

BY WALTER B JOHNSON, M.D. PATERSON, N. J.

J. H. H., 23 years old, consulted the writer on Sept. 5,1889 stating that he suffered from a very peculiar form of disease of the nervous system for which he had been amined and treated during the past two years by a lar prominent physicians. He was in good phys attended to his business as a salesman regula discomfort, except slight headache, until $t$ which he wished treatment came on, two y that time, at intervals varying from two months, he had had attacks, the onset of whic beadache coming on suddenly and without an premonition and followed by loss of all conscious mental action. The patient had no recollection, when recovering from the attack, of anything except the intial headache. The time during which he remained in the state of conscious mental inactiv. ity varied from two to five days; during this time he would, if the attack seized him on the street, have been able to care for bimself, as in such cases he invariably had sufficient money remaining to indicate the expenditure of enough only to have paid expenses during the time which was a blank to him. On returning to conscious mental activity he generally, upon awaking in the morning, found himself in some hotel in the city which he had not been accustomed to frequent. If the attack seized him at home the improvement in the headache, which occurred generally in two or three hours, was followed by a profound sleep which lasted until the following day, or in extreme cases, two days, the headache frequently returning on the morning of the second day. When the stupor passed away he was able to resume his work as usual.

The physicians consulted by him differed in opinion regarding the nature of the attack, Dr. A. L. Loomis and the major portion diagnosing the disease epilepsy, while others considered it neurotic and only epileptiform in character.

Upon the recommendation of his physician, he concluded to consult further with a view to excluding any abnormal ocular condition as an etiologic factor in the production of his disorder. He applied for treatment in September, 1889. The case was of such marked interest that a consultation was considered advisable, and the several consultants reported the details of their examinations as follows :

Dr. Herman Knapp, New York: Slight dynamic inversion not verified with prisms for near.

Dr. David Webster, New York: R., 25 D. C. ax. 90; eso- phoria $2^{\circ}$ in acc. L., 25 D. sph.; exophoria $20^{\circ}$; abduction $5^{\circ}$ Under atropin, R., 50 D. C. ax. $90^{\circ}$ c, 0.50 D. c. ax. $180^{\circ}$. L., 0.25 D. $\mathrm{sph}$

Dr. Geo. T. Stevens, New York, before and after atropin: R., 0.75 D. C. ax. 180 ; esophoria, 50. L., 0. 5 D. C. ax. 180; abduction $2^{\circ}$, later $0^{\circ}$.

Homonymous diplopia. The result of thr examination of the writer was: R. V., $20-30-20-15$ 1. D. c ax. 180. L. V., 20-15-20-15 w. 0.75 D. sph.

With this correction, the lines upon the test chart for astigmatism were all of an equal density aid thickness, the vision normal. Esophoria $5^{\circ}$; abduction $5^{\circ}$.

Homonymous diplopia at distance. The diplopia was not present at the near point, either with or without the correcting glasses, which were ordered and the patient directed to wear them continuously. R., 1 D. C. ax. 180 . I., $0.75 \mathrm{sph}$. For some time after the glasses were prescribed and worn the patient was decidedly improved, his general condition was much better and he had none of the attacks previously described. Finally, the primary effect of the glasses passed away and the epileptic seizures returned with as much frequency and force as previously existed. The partial tenotomy of the internal recti muscles advised by Dr. Geo. T. Stevens was then performed. The eyes were tested immediately after the tenotomy and showed a slight degree of exophoria. The patient was directed to wear his glasses continuously and report. He remained in the city for two months, during which time there was no return of the attacks herein described; although he at times suffered from headache, he had none resembling those which occurred at the onset of an epileptic seizure, nor any stupor or loss of conscious mental activity following.

April 23,1895 . In a letter written from his present home in Chicago, he states that he never has had any attacks of epilepsy since the last record, and is a different person from the one I knew in this city.

\section{A RETROSPECTIVE VIEW OF THE TREAT. MENT OF HEMORRHOIDS.}

\section{BY N. H. HENDERSON, M.D.}

SURGEON LAKESIDE HOSPITAL, CHICAGO.

It is only within the past few years that diseases of the rectum have received the attention to which they are entitled. Until about twenty years ago the only possible source of relief from hemorrhoids was the clamp and cautery or the ligature. To attempt any surgical operation was considered very dangerous, and, in fact, we have evidence of many cases where fatal hemorrhage was the result of surgical procedure. Surgeons approached the field with timidity, and during our college course instruction pertaining to diseases of the rectum were the exception, and not rule, and were mainly confined to prescriptions for some palliative ointment, with no assurance, nor even expectation of cure. It is an acknowiedged fact that the first step forward in the treatment of hem. orrhoids was the hypodermic injection of carbolic acid, or any styptic that we saw fit to employ. The regular practitioner was slow to accept this innovation, owing to its origin in the hands of the itinerant, but the success of the measure at length compelled the recognition of the profession. For at least eighteen years my associate, Dr. E. H. Dorland, has treated hemorrhoids by the method of injection and continues the practice in suitable cases up to the present date. The next step toward reformation was the Whitehead operation. Then Dr. E. H. Pratt reversed the "Whitehead" and gave it prominence under the name of the "American." To recapitulate, we have the clamp and cautery, the ligature, the Whitehead and the American, to which I wish to add the operation described by me in the JOURNAL OF THE American Medical Association of Feb. 23, 1895 . A brief notice of the above operations may at least en- 